\title{
Head Equivalent Liquids: A Review on Composing, Recipes and Standards
}

\author{
Ugur Sorgucu ${ }^{1}$, Ibrahim Develi ${ }^{2}$ \\ ${ }^{1}$ Bartin University \\ Faculty of Engineering, Bartin University, Bartın, Turkey \\ sorgucu@bartin.edu.tr \\ ${ }^{2}$ Erciyes University \\ Faculty of Engineering, Erciyes University, Kayseri, Turkey \\ develi@erciyes.edu.tr
}

\begin{abstract}
Most of the electric-powered devices and systems emit electromagnetic energy to their environment. The main risk related to the absorption of this energy by biological bodies is commonly assumed to be the temperature rise. Investigation of temperature rise on human body, likely to occur during exposure to electromagnetic fields, conflicts with the code of ethics in academic research. This has led to the need for production of tissue equivalent liquids. Preparation of tissue equivalent liquids, used for determination of hyperthermia and dosimetry values, as well as the SAR (Specific Absorption Rate) values of the cell phones, requires high precision. The present study summarizes how to achieve a tissue equivalent liquid with references to recent progress in the literature with a view to become a pioneering effort for all researchers working in the field.
\end{abstract}

Keywords: Head Equivalent Liquids, Tissue Equivalent Liquids, Biological tissues.

\section{Introduction}

The issue of permanent exposure of millions of people to electromagnetic field sources has drawn the attention and interest of the scientific world to possible health risks. Many of the electric powered devices and systems emit electromagnetic energy to their environment. The impulses that enable the functioning of brain are within the range of 1-250 micro-volt. In consideration of the effects of environmental factors on such a sensitive system, the researchers have put particular emphasis on the importance of the studies on the effect of electromagnetic pollution on the brain, in addition to air and noise pollution [1-3].

SAR calculations of electromagnetic fields, as well as dosimetry and hyperthermia studies cannot be conducted experimentally on human body, since it conflicts with the code of ethics in academic research besides its impracticability [4]. Therefore production of the mixtures equivalent to human physiology has become a necessity. For his purpose, there is a demand for tissue equivalent liquids as a means for investigation of the electromagnetic field effects on biological tissues [5-8]. The recent researches on the electrical characteristics of the tissues, in fact date back to 1950s. The general theoretical concept as well as many fundamental findings was obtained in light of these studies [9-15]. However, as emphasised in the studies of Schwan and Foster in 1950s, the studies on the subject date back to earlier years [11, 16].

During the preparation of head equivalent tissue, an average human's statistically specified antrophormic head structure is assumed [17]. However, the head structure of an average human alone is not applicable for electrical imitation of the head region, since the electromagnetic field distribution within the biological tissue depends on the electrical characteristics (relative permeability and conductivity) [18-20]. Accordingly, a liquid material is used for enabling electrical imitation of the head region by this antrophormic head model [21]. This liquid, having identical electrical characteristics with the tissue within the head, is called Head Equivalent Liquid (HEL).

A variety of methods is used for preparation of HEL. The main issue encountered during the preparation stage is degradation and decomposition of TX150 or TX150 used as gelling agents and the ingredients of the mixture. In light of this, TX-151 is stated as the main reason that underlies the main problem in previous researches in the literature [22, 23]. HELs are prepared in different forms for each frequency region [22-24]. This is attributed to the frequency dependent behaviour of 
the electrical characteristic of the tissues $[25,26]$. The electrical characteristics of the tissues are detailed in the standards IEEE 1528 and IEC 62209-2. Frequency dependent electrical behaviour of HEL is given in Table 1.

Table 1: Electrical characteristics of some well-known head tissues [27, 28].

\begin{tabular}{|c|c|c|c|c|}
\hline \multirow[b]{2}{*}{$\begin{array}{l}\text { Frequency } \\
(\mathrm{MHz})\end{array}$} & \multicolumn{2}{|l|}{ IEEE 1528} & \multicolumn{2}{|l|}{ IEC 62209-2 } \\
\hline & $\begin{array}{l}\text { Relative } \\
\text { permeability }\end{array}$ & $\begin{array}{l}\text { Conductivity } \\
(\mathrm{S} / \mathrm{m})\end{array}$ & $\begin{array}{l}\text { Relative } \\
\text { permeability }\end{array}$ & $\begin{array}{l}\text { Conductivity } \\
(\mathrm{S} / \mathrm{m})\end{array}$ \\
\hline 300 & 45.3 & 0.87 & 45.3 & 0.87 \\
\hline 450 & 43.5 & 0.87 & 43.5 & 0.87 \\
\hline 750 & - & - & 41.9 & 0.89 \\
\hline 835 & 41.5 & 0.90 & 41.5 & 0.90 \\
\hline 900 & 41.5 & 0.97 & 41.5 & 0.97 \\
\hline 1450 & 40.0 & 1.20 & 40.5 & 1.20 \\
\hline 1800 & 40.0 & 1.40 & 40.0 & 1.40 \\
\hline 1900 & 40.0 & 1.40 & 40.0 & 1.40 \\
\hline 1950 & - & - & 40.0 & 1.40 \\
\hline 2000 & 40.0 & 1.40 & 40.0 & 1.40 \\
\hline 2100 & - & - & 39.8 & 1.49 \\
\hline 2450 & 39.2 & 1.80 & 39.2 & 1.80 \\
\hline 2600 & - & - & 39.0 & 1.96 \\
\hline 3000 & 38.5 & 2.40 & 38.5 & 2.40 \\
\hline
\end{tabular}

HEC (Hydroxyl Ethyl Cellulose) is used to increase the viscosity of HEL, which has a low viscosity due to the use of water as its main constituent. Through use of this material the desired viscosity is obtained in a wide range [29]. As another constituent of HEL, $\mathrm{NaCl}$ (Sodium Chloride) is used in small quantities in granular form to regulate conductivity. Sucrose is used as the main constituent to decrease the high relative permeability of pure water. The solutions prepared using saccharic chemicals are used with bactericides to prevent decomposition and stench [30, 31]. DGBE is used as another constituent especially for the phantoms prepared for high frequencies, since relative permeability can not be decreased by use of sucrose beyond a level.

\section{Composing Head Equivalent Liquids (HELs)}

The electrical characteristics of the prepared HELs can be adjusted to desired values. Generally the increasing amount of salt increases the conductivity and the amount of water within HEL is effective on relative permeability. Limitations on these materials are conducted independent of each other $[32,33]$. However no literature information is available on whether other chemicals have similar effect.

Information on the electrical characteristics of the tissues can be obtained from [34, 35]. The main issue to be regarded during the preparation of tissue models being used in the researches is ensuring that the electrical characteristic of the prepared phantom and the electrical values expected within the device's operating frequency are close. Otherwise one cannot assert that a HEL imitates a tissue, and reliability of the working results become disputable. In the literature some of the studies suggest that deviations of $5 \%$ and $10 \%$ are acceptable for relative permeability and conductivity, respectively, as a result of the measurements conducted by open-ended probes [36, 37].

HELs used in electromagnetic field exposure studies usually have similar characteristics. These tissues are generally prepared considering equivalent tissue characteristics under room temperature, since the electrical parameters of the equivalent tissues exhibit temperature dependent behaviour. With increasing temperature, the relative permeability decreases 
at a rate of $0.5 \%$ in the tissues with high water content, whereas conductivity increases by $2 \%$ [37]. A few fundamental methods are available for preparation of equivalent mixtures of tissues such as brain and muscle which have high water content compared to other tissues. One is the HEL mixture in the form of opaque gel, (content: water, salt, polyethylene powder and gelling agent), and the other is composed of water, sugar, salt and HEC (Hydroxyl Ethyl Cellulose) for viscosity of the mixture. Different chemical compounds are used in acquiring HEL for biological tissues [8, 22-24, 27, 34]. Some of the HELs prepared for $900 \mathrm{MHZ}$ frequency using different chemicals by various researchers, are given in Table 2.

Table 2: Major HEL samples prepared using different chemicals for $900 \mathrm{MHz}$ frequency.

\begin{tabular}{|c|c|c|c|c|c|c|c|c|c|c|}
\hline $\begin{array}{l}\text { The } \\
\text { Chemicals } \\
\text { Used } \\
\text { Samples } \\
\text { of HEL }\end{array}$ & 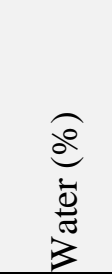 & 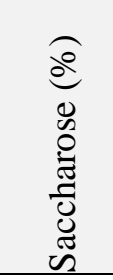 & 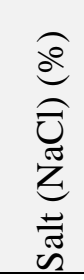 & 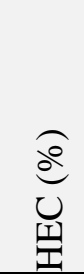 & 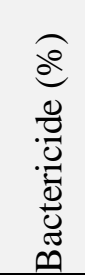 & $\begin{array}{l}\hat{\sigma} \\
\stackrel{0}{n} \\
\stackrel{n}{x} \\
\hat{n}\end{array}$ & 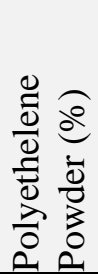 & 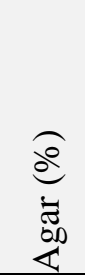 & 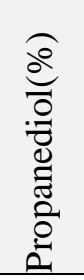 & $\begin{array}{c}\frac{0}{0} \\
0 \\
\frac{0}{0} \\
\frac{0}{0}\end{array}$ \\
\hline Presented in [8] & 43.55 & 54.66 & 0.72 & 0.90 & 0.17 & & & & & \\
\hline Presented in [27] & 40.92 & 56.50 & 1.48 & 1.00 & 0.10 & & & & & \\
\hline Presented in [36] & 36.31 & & 1.12 & & & & 3.74 & 5.35 & & 53.48 \\
\hline Presented in [38] & 40.30 & 57.00 & 1.38 & 0.24 & 0.18 & & & & & \\
\hline Presented in [39] & 62.61 & & 0.53 & & & 7.01 & 2. & & & \\
\hline Presented in [40] & 34.40 & & & 0.70 & & & & & 4.81 & \\
\hline
\end{tabular}

As seen in Table 2, it is possible to acquire HEL using different chemicals. However, HEL preparation process is much more complex than mixing specific chemicals in specific ratios. Indeed, the researchers that prepared the phantoms given in Table 2, encountered deviations with some phantoms, despite having intended to provide the electrical characteristic specified in standards IEEE 1528 and IEC 62209-2. Many of previous studies have focused on a specific frequency domain. For instance, in [8] the relative permeability of the phantom prepared for $900 \mathrm{MHz}$ was found as 44 instead of 41.5 , and conductivity value was found as $0.92 \mathrm{~S} / \mathrm{m}$ instead of $0.97 \mathrm{~S} / \mathrm{m}$. The obtained relative permeability value represents the behaviour of brain at approximately $350 \mathrm{MHz}$, whereas the conductivity value of 0.92 indicates the conductivity value of brain at $850 \mathrm{MHz}$. Also relative permeability value was found to exceed the acceptable deviation of 5\% stated in [41]. Another study on HEL is presented in [40]. Phantoms were prepared for 14 different frequency domains, and relative permeability and conductivity values of the prepared phantoms were measured. All measurements were resulted in agreement with IEEE standards with a deviation of 2\%. In [39] the researchers that used the chemicals such as propane diol and dacetine which are not available in all laboratories, made considerable contribution to the literature in proving that a wide range of chemicals can be used in preparation of HEL, however they have not suggested alternative HEL models for researches with limited laboratory resources. However, protective agents such as triclosan, isopropyl alcohol and formaldehyde are also used as a means to prevent mold and bacteria growth instead of propanediol in the phantoms prepared in [40]. Also preparation of only one chemical formulation for each frequency domain is interpreted as a shortcoming in [40]. Indeed, no information is given on the ratio of a chemical used as a substituent of another, in preparation of phantoms.

\section{Measurement of Electrical Values of HELs}

In the case of preparation of a HEL imitating the brain, the phantom prepared in gel form shall have the relative permeability and conduction values specified in [35]. However the electrical values of the phantom is susceptible to all changes in the HEL temperature or the changes with a precision of 0.001 within its chemical composition. In addition, some of the chemical within its content is only effective on relative permeability, whereas others may be effective on both relative permeability and conductivity. Accordingly, determination of the effect of each parameter on the HEL characteristic is crucial. There is more than one method suggested by IEEE for determination of electrical characteristics of the phantoms. 
These are; (i) Use of vector network analyser and S-parameter test set, (ii) use of dielectric test cell also known as sample holder or dielectric probes and (iii) use of S parameter and synchronous custom software.

\section{Conclusion}

In this paper, the need for preparation of head equivalent liquids is presented with an extensive literature database. Also, the challenges encountered during preparation of equivalent tissues commonly used in the scientific fields such as dosimetry, hyperthermia and SAR calculation, are also addressed and suggestions are made as to the measures to be taken. Additionally, instances of HELs prepared in previous researches are given and their differences are stated. A thorough review of this study by researchers within the related field will be useful in foreseeing a great deal of problems.

\section{Acknowledgements}

This paper has presented a literature review as a first step for TUBITAK project No 115E221.

\section{References}

[1] K. Atasoy, "GSM System and Health (in Turkish)," Gazi University, Dept. of Physic-Research Project, Ankara, Turkey, 2006.

[2] K. Lias, D. A. A. Mat, K. Kipli, and A. S. W. Marzuki, "Human Health Implication of $900 \mathrm{MHz}$ and $1800 \mathrm{MHz}$ Mobile Phones," in Proceedings of The 2009 IEEE 9th Malaysia, International Conference on Communications, Kuala Lumpur, Malaysia, 2009, pp. 146-149.

[3] S. S. Seker and O. Cerezci, "Radiation around us and Prevention Methods (in Turkish)," Second Edition, Bogazici University Publications, Publication No: 607, İstanbul, 1997.

[4] Turkey Medicine and Medical Devices Agency, "Regulation on Clinical Trials (in Turkish)," Official Gazette of the Republic of Turkey No: 28617," 2013.

[5] D. Simunic, J. Bartolic, and S. Skokie, "Influence of Measured Dielectric Properties to SAR Values," in Proceedings of PIERS 2002, 2002, pp. 502, Cambridge, Massachusetts, USA.

[6] M. H. Bandar. "Precise Sar Measurements in the Near-Field of RF Antenna Systems," University of Maryland, Phd. Thesis, 144 pages, 2006.

[7] K. Fukunaga, S. Watanabe, and Y. Yamanaka, "Dielectric Properties of Tissue Equivalent Liquids and Their Effects on Electromagnetic Power Absorption," in IEEE 2002 Annual Report Conference on Electrical Insulation and Dielectric Phenomena, 2002, pp. 75- 78.

[8] S. Ozen and H. Koylu, "Phantom Model of Human Brain Tissue for Cellular Phone Frequencies in Electromagnetic Field Radiation Absorption Studies," Gazi University Journal of Science, vol. 18, pp. 193-200, 2005.

[9] H. F. Cook, "The Dielectric Behaviour of Some Types of Human Tissues at Microwave Frequencies," British Journal of Applicational Physics, vol. 2, pp. 295-300, 1951.

[10] T. S. England, "Dielectric Properties of the Human Body for Wavelengths in the 1-10 cm Range," Nature, vol. 166, pp. 480-481, 1950.

[11] H. P. Schwan, "Electrical Properties Measured with Alternating Currents; Body Tissues," in Handbook of Biological Data Edition, W. B. Saunders, Philadelphia, Pa, USA. 1956.

[12] W. S. Spector and H. P. Schwan, "Electrical Characteristics of Tissues: A Survey," Biophysik, vol. 1, pp. 1198-1208, 1963.

[13] H. P. Schwan and G. M. Piersol, "The Absorption of Electromagnetic Energy in Body Tissues," American Journal of Physical Medicine and Rehabilitation, vol. 33, pp. 371-404, 1954.

[14] M. A. Stuchly and S. S. Stuchly, "Electrical Properties of Biological Substances," in Biological Effects and Medical Applications of Electromagnetic Energy, Englewood Cliffs, NJ: Prentice Hall, pp. 75-112, 1990.

[15] K. R. Foster and H. P. Schwan, "Dielectric Properties of Tissues and Biological Materials, A Critical Review," Critical Review in Biomedical Engineering, vol. 17, pp. 25-104, 1989.

[16] K. R. Foster, J. L. Schepps, R. D. Stoy, and H. P. Schwan, "Dielectric Properties of Brain Tissue Between 0.01 and $10 \mathrm{GHz}, "$ Physics in Medicine and Biology, vol. 24, pp. 1177-1187, 1979.

[17] C. C. Gordon, T. Churchill, C. E. Clauser, B. Bradtmiller, J. T. McConville, I. Tebbetts, and R. A. Walker, IEEE Recommended Practice for Determining the Peak Spatial Average Specii c Absorption Rate (SAR) in the Human Head 
from Wireless Communications Devices-Measurement Techniques. NewYork, USA: The Institute of Electrical and Electronics Engineers, Inc., 2003.

[18] Application Note, "Agilent Basics of Measuring the Dielectric Properties of Materials," Agilent Literature Number 5989-2589 EN, 2006.

[19] K. M. Chew, R. Sudirman, N. Seman, and C. Y. Yong, "Human Brain Phantom Modelling Based on Relative Permittivity Dielectric Properties," in International Conference on Biomedical Engineering and Biotechnology, pp. 817-820, China, 2012.

[20] A. Drossos, V. Santomaa, and N. Kuster, "The Dependence of Electromagnetic Energy Absorption upon Human Head Tissue Composition in the Frequency Range of 300-3000 MHz," in IEEE Transactions on Microwave Theory and Techniques, vol. 48, pp. 1988-1995, 2000.

[21] U.S. Army Natick Research Development and Engineering Center, "Anthropometric Survey of U.S. Army Personnel: Methods and Summary Statistics,” Technical Report, NATICK/TR-89/044, Natick Massachusetts, USA, 1988.

[22] G. Hartsgrove, A. Kraszewski, and A. Surowiec, "Simulated Biological Materials for Electromagnetic Radiation Absorption Studies," Bioelectromagnetics, vol 8, pp. 26-36, 1997.

[23] V. Vigneras, "Elaboration and Characterization of Biological Tissues Equivalent Liquids in the Frequency Range 0.9$3 \mathrm{GHz}$," Final Report Bordeaux, France, 2011.

[24] M. Y. Kanda, M. Ballen, C. Chou, and Q. Balzano, "Formulation and Characterization of Tissue Equivalent Liquids Used for RF Densitometry and Dosimetry Measurements," in IEEE Transactions on Microwave Theory and Techniques, vol. 52, pp. 2046-2056, 2004.

[25] C. K. Chou, G. W. Chen, A. W. Guy, and K. H. Luk, "Formulas for Preparing Phantom Muscle Tissue at Various Radiofrequencies," Bioelectromagnetics, vol. 5, pp. 435-441, 1984.

[26] M. Y. Kanda, M. Ballen, C. Chou, and Q. Balzano, "Formulation and Characterization of Tissue Simulating Liquids Used for SAR Measurement (500 - 2000 MHz)," in Asia-Pacific Radio Science Conference, Tokyo, Japan, pp. 274, 2001.

[27] IEEE Standard 1528, "IEEE Recommended Practice for Determining the Peak Spatial-Average Specific Absorption Rate (SAR) in the Human Head from Wireless Communications Devices: Measurement Techniques," 2013.

[28] The International Electro technical Commission (IEC), IEC 62209-2 International Standard, "Human exposure to radio frequency fields from hand-held and body-mounted wireless communication devices - Human models, instrumentation, and procedures - Part 2: Procedure to determine the specific absorption rate (SAR) for wireless communication devices used in close proximity to the human body (frequency range of $30 \mathrm{MHz}$ to $6 \mathrm{GHz}$ ), " 2010.

[29] J. H. Kim and Y. M. Gimm, "Complex Permittivity Measure Using a Coaxial Slotted Line of Reference Liquids at Mobile Communication Frequencies," in Asia-Pacific Microwave Conference, Seoul, Korea, pp. 2024-2027, 2003.

[30] Y. M. Gimm, "General Method of Formulating The Human Tissue Simulant Liquid for SAR Measurement," in Emc International Symposium on Electromagnetic Compatibility, Netherland, vol. 2, pp. 561-564, 2004.

[31] M. Ballen, M. Kanda, C. K. Chou, and Q. Balzano, "Formulation and Characterization of Tissue Simulating Liquids Used for SAR Measurement," in Protective Bioelectromagnetics Society 23rd Annual Meeting, vol. 14, pp. 80-81, 2001.

[32] S. Ozen, "Theoretical and Experimental Investigation of Thermal Effect that Occurs in Biological Tissues in Exposing to Microwave Frequency Electromagnetic Radiation (in Turkish)," Sakarya University, Institute of Science and Technology, Phd Thesis, 2003.

[33] D. Simunic and Z. Glavas, "SAR Measurements of Different Mixtures at $900 \mathrm{MHz}$," in 12th IMEKO TC4 International Symposium, Zagreb, Croatia, pp. 235-238, 2002.

[34] R. F. Reinoso, B. A. Telfer, and M. Rowland, "Tissue Water Content in Rats Measured by Desiccation," Journal of Pharmacological and Toxicological Methods, vol. 38, pp. 87-92, 1997.

[35] J. L. Ulcek and R. F. Clevand, Federal Communication Commission Office of Engineering \& Technology, Information on Human Exposure to Radiofrequency Fields from Cellular and PCS Radio Transmitters. Washington: Bulletin 65, Editions, pp. 97-101, 1997.

[36] Y. Okano, A. Hase, and K. Ito, "A Brain-Equivalent Solid Phantom and Its Application to SAR Estimation by the Thermographic Method," Electronics and Communications in Japan Part II-Electronics, vol. 83, pp. 24-34, 2000.

[37] H. H. Suzana, "The Human Brain in Numbers: a Linearly Scaled-up Primate Brain," Frontiers in Human Neuroscience, vol. 3, no. 31, 2009. 
[38] K. Fukunaga, S. Watanabe, Y. Yamanaka, "Dielectric Properties of Tissue-Equivalent Liquids and Their Effects on Specific Absorption Rate," IEEE Transactions on Electromagnetic Compatibility, vol. 46, pp. 126-129, 2004.

[39] C. H. Durney, H. Massoudi, M. F. Iskender, "Radiofrequency Dosimetry Handbook (4th Edition)," Texas: Brooks Air Fors Base, 1986.

[40] M. G. Douglas, M. Ballen, C. K. Chou, "Temperature Sensivity of Tissue Equivalent Liquids Used for SAR Testing," BIOEM 2013, Thessabniki, Greece, pp. 304-305, 2013

[41] O. P. Gandhi, G. Lazzi, A. Tinniswood, Q. S. Yu, "Comparison of Numerical and Experimental Methods for Determination of SAR and Radiation Patterns of Handheld Wireless Telephones," Bioelectromagetics, vol. 20, pp. 93-101, 1999. 